\title{
Lovastatin production by Aspergillus fischeri under solid state fermentation from coconut oil cake
}

\author{
Parvatham Madhu Latha $^{1^{*}}$, Pallem Chanakya ${ }^{2}$, Manipati Srikanth ${ }^{3}$
}

\footnotetext{
${ }^{1, *}$ NRI College of Pharmacy, Pothavarappadu, Agiripalli Mandal, Vijayawada Rural, Andhra Pradesh.

${ }^{2}$ Centre for Biotechnology, Department of Chemical Engineering,

AU College of Engineering (A), Andhra University, Visakhapatnam, Andhra Pradesh.

${ }^{3}$ NRI Academy of Medical Sciences, China Kakani, Mangalagiri Mandal, Guntur, Andhra Pradesh

*Corresponding author: srimani.nri@gmail.com, chanakya.pallem@gmail.com
}

\begin{abstract}
:
The main aim of the present investigation was to optimize the fermentation parameters that enhance the maximum production of lovastatin by Aspergillus fischeri using coconut oil cake as the solid substrate under solid state fermentation. The maximum yield of lovastatin $(14.77 \mathrm{mg} / \mathrm{g}$ dry substrate) using coconut oil cake as the substrate was achieved with the following optimized process parameters: fermentation time ( 7 days), initial moisture content $(60 \% \mathrm{v} / \mathrm{w})$, inoculum volume $\left(2 \mathrm{ml}\right.$ of five day old culture), initial $\mathrm{pH}(5.0)$, incubation temperature $\left(30^{\circ} \mathrm{C}\right)$, lactose $(1 \%$ $\mathrm{w} / \mathrm{v})$ and malt extract $(1 \% \mathrm{w} / \mathrm{v})$.
\end{abstract}

Keywords: Lovastatin, Aspergillus fischeri, Coconut oil cake, Fermentation parameters, Optimization

\section{Introduction:}

Lovastatin also called as Mevinolin, Monacolin K and Mevacor, a kind of fungal metabolite, serves as one of the competitive inhibitors of enzyme hydroxymethylglutaryl coenzyme A reductase (HMG-CoA), which catalyzes the rate-limiting step in cholesterol biosynthesis, resulting in lowered blood cholesterol [1,2]. In addition, lovastatin has been used in the biomedical applications such as, in treating coronary heart diseases, renal diseases, Alzheimer's disease, bone fractions [3]. Moreover, it has been indicated as a potential therapeutic agent for the treatment of various types of tumors because of its capability to suppress tumor growth in vivo through inhibition of the synthesis of nonsterol isoprenoid compounds $[4,5]$.

Commercial production of lovastatin has been carried out by submerged fermentation using different microorganisms $[6,7]$. In recent 
years, researchers have shown an increasing interest in solid state fermentation (SSF) as it is a potential alternative of submerged fermentation because economical and cheap substrates can be utilized in SSF for production of value-added products, and also requires less energy, and low capital costs. Now days, SSF has been exploited for the production of highly potent drugs on large scale. But still, few reports are available on the microbial production of lovastatin under SSF [8-10].

In the present study, we evaluated the feasibility of SSF process for lovastatin production by Aspergillus fischeri and optimized different process parameters that maximize the lovastatin yield.

\section{Materials and Methods}

\section{Microorganism and Inoculum preparation:}

The fungal strain Aspergillus fischeri NCIM 509 used in this study was procured from the culture collection centre of National Collection of Industrial Microorganisms (NCIM), NCL, Pune. The microbial strain was maintained on Potato Dextrose Agar (PDA) slants containing (g/l) dextrose 20.0 and agar 15.0. Inoculated slants were grown in an incubator at $28^{\circ} \mathrm{C}$ for 5 days. After that, the slants were preserved at $4^{\circ} \mathrm{C}$ and sub-cultured once every four weeks (monthly).

\section{Inoculum preparation:}

Inoculum was prepared by adding $10 \mathrm{ml}$ of sterilized $0.1 \%$ Tween 80 solution to a wellsporulated A. fischeri slant. The spore surface was scrapped with an inoculating loop to suspend the spores in the solution and the obtained spore suspension was used as the inoculum for the fermentation process.

\section{Solid state fermentation (SSF):}

Coconut oil cake obtained from the local market of Vijayawada, Andhra Pradesh was used as the substrate in the present study. Five grams of coconut oil cake was dried and grounded to required particle size having both coarse and fine particles in 1:1 ratio $(\mathrm{w} / \mathrm{w})$. The substrate was taken in a $250 \mathrm{ml}$ Erlenmeyer flask and moistened with distilled water to maintain the moisture content of $50 \%$ $(\mathrm{v} / \mathrm{w})$ and autoclaved at $121^{\circ} \mathrm{C}(15 \mathrm{lb})$ for $15-$ $20 \mathrm{~min}$, cooled to room temperature and inoculated with $2 \mathrm{ml}$ of the 5 day spore suspension (spore concentration of about $10^{7}-10^{8}$ per $\mathrm{ml}$ ) of $A$. fischeri under aseptic conditions. The contents of the inoculated flasks were mixed thoroughly and incubated at desired temperature in an incubator for desired length of fermentation time. 


\section{Optimization of Process Parameters:}

Various process parameters that influence the lovastatin production during SSF were optimized over a wide range. The strategy adopted for standardization of fermentation parameters was to evaluate the effect of an individual parameter and incorporate it at the standard level before standardizing the next parameter. The process parameters optimized in the present study include fermentation time (24-192h), initial moisture content (40-100\% $\mathrm{v} / \mathrm{w})$, inoculum volume $(0.5-4 \mathrm{ml})$, initial $\mathrm{pH}$ (4-10), incubation temperature $\left(26-40^{\circ} \mathrm{C}\right)$, carbon sources $(1 \% \mathrm{w} / \mathrm{v})$ and nitrogen sources $(1 \% \mathrm{w} / \mathrm{v})$. All the experiments were done in triplicate and the mean values of the lovastatin yield was reported.

\section{Lovastatin extraction:}

After the fermentation time, the fermented flasks were dried at $60^{\circ} \mathrm{C}$ for $2 \mathrm{hrs}$. To this $20 \mathrm{ml}$ of methanol was added to the flasks to extract lovastatin by keeping them in an orbital shaker at $180 \mathrm{rpm}$ for $2 \mathrm{~h}$. The residue was filtered with filter paper and then centrifuged at $1500 \mathrm{rpm}$ for 15 min. The supernatant obtained was collected and analyzed for quantitative determination of lovastatin [10].

\section{Quantitative analysis of lovastatin:}

To $1 \mathrm{ml}$ of the obtained supernatant, $1 \mathrm{ml}$ of $1 \%$ Trifloroacetic acid was added and incubated for $10 \mathrm{~min}$ (Lactonization of hydroxyl acid form of Lovastatin).From the solution, $0.5 \mathrm{ml}$ was taken and diluted to $10-$ $100 \mathrm{ml}$ in methanol and its absorbance was read at $238 \mathrm{~nm}$ by using UV-Visible Spectrophotometer [11].

$$
\text { Concentration of Lovastatin }(\mathrm{mg} / \mathrm{g})=\frac{\text { Concentration of Lovastatin }(\mathrm{mg} / \mathrm{ml}) \times \text { Dilution factor }(\mathrm{DF})}{\text { Amount of substrate taken }(\mathrm{g})}
$$

\section{Results and Discussion}

\section{Selection of solid substrates in SSF for lovastatin production:}

Solid substrates employed in SSF processes are heterogeneous natural raw-materials which are generally insoluble in water and play a dual role-supply of nutrients to the microbial culture growing and anchorage for the growing cells. In the present study, coconut oil cake was used as the solid substrate for both the fungal sporulation and lovastatin production by Aspergillus fischeri. Maximum 
lovastatin yield of $6.81 \mathrm{mg} / \mathrm{g}$ dry substrate was obtained.

\section{Effect of Fermentation time:}

The effect of fermentation time on lovastatin production was studied by incubating the fermentation flasks from 24-192 h. The maximum lovastatin yield of $7.43 \mathrm{mg} / \mathrm{g}$ of dry substrate was achieved at $168 \mathrm{~h}$ of fermentation time (Fig.1). The lovastatin yield increased from 24-168 $\mathrm{h}$ which explained that lovastatin is a kind of secondary metabolite and its accumulation in mycelia seems growth related and slightly decreased from 168-192h. The lovastatin yield decreased after seven days (168 h) of fermentation which may be due to the onset of death phase of microorganism and nutrient depletion.

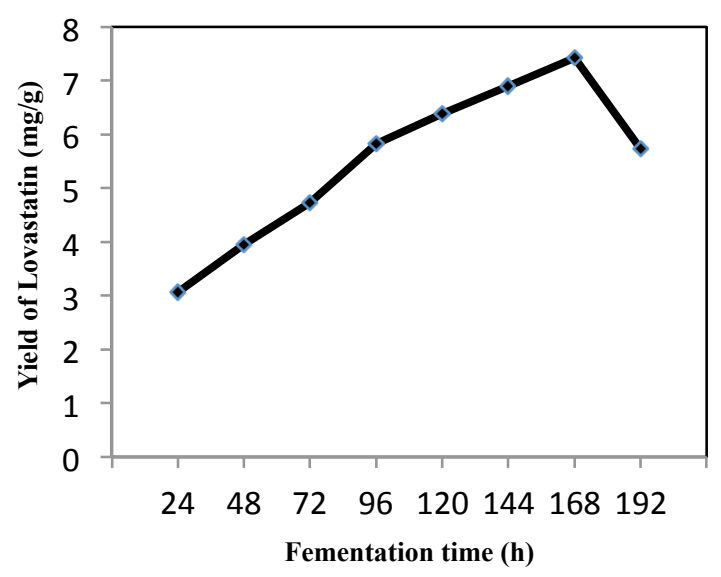

Fig.1: Effect of fermentation time on lovastatin production

\section{Effect of initial moisture content}

To investigate the influence of initial moisture content of the substrate, fermentation was carried out under various initial moisture content levels $(40,50,60$, $70,80,90$ and $100(\% \mathrm{v} / \mathrm{w}))$ of coconut oil cake, which was adjusted with moistening media. Maximum lovastatin yield (8.04 $\mathrm{mg} / \mathrm{g}$ dry substrate) was achieved at $60 \%$ (v/w) initial moisture content ( Fig. 2.).

As the moisture content in the fermentation medium increases, the air present in the void volume decreases, resulting in poor oxygen availability for the process without forced aeration and with low moisture content, the available oxygen is sufficient but the water content is not enough to support good metabolic activity and dissipation of heat generated and may account for lower lovastatin production. The same $60 \%(\mathrm{v} / \mathrm{w})$ moisture content was also observed for both Aspergillus flavipes and Aspergillus terreus under SSF $[8,10]$. 


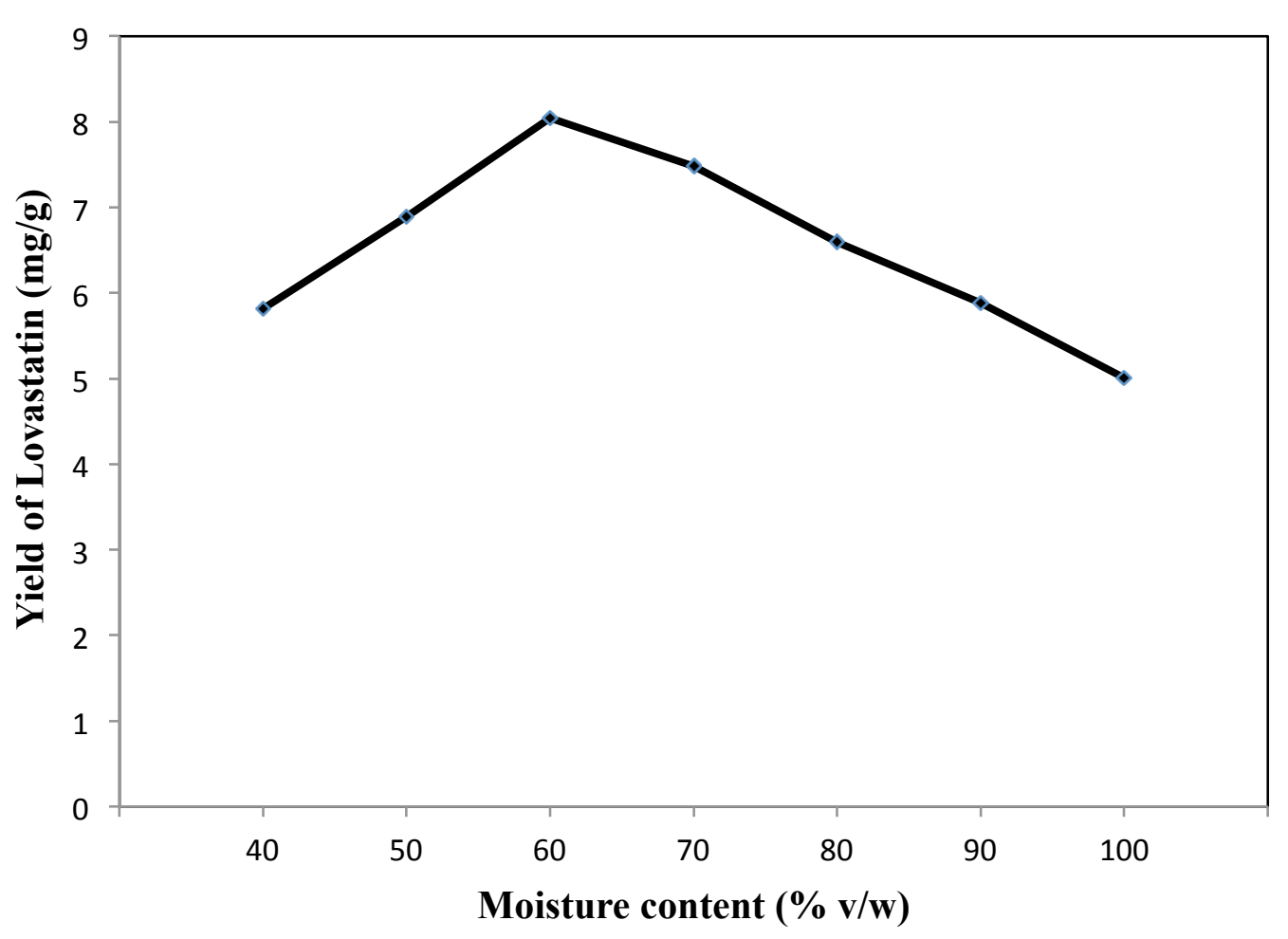

Fig. 2: Effect of moisture content on lovastatin production

\section{Effect of Inoculum volume}

Fermentation was carried out with different inoculum volumes $(0.5-4 \mathrm{ml})$ of five day old A. fischeri culture for a period of $144 \mathrm{~h}$ to study its effect on lovastatin production. The maximum yield of lovastation $(8.97 \mathrm{mg} / \mathrm{g}$ dry substrate) was obtained with $2 \mathrm{ml}$ of A.fischeri culture as shown in Fig. 3.
With the further increase in inoculum volume, the yield of lovastatin had decreased which might be due to the depletion of the available nutrients in the production medium, yielding poor mycelia growth, thus promoting less product formation. With low inoculum volume, the yield is also low due to the insufficient microbial culture to form mycelia and produce lovastatin. 


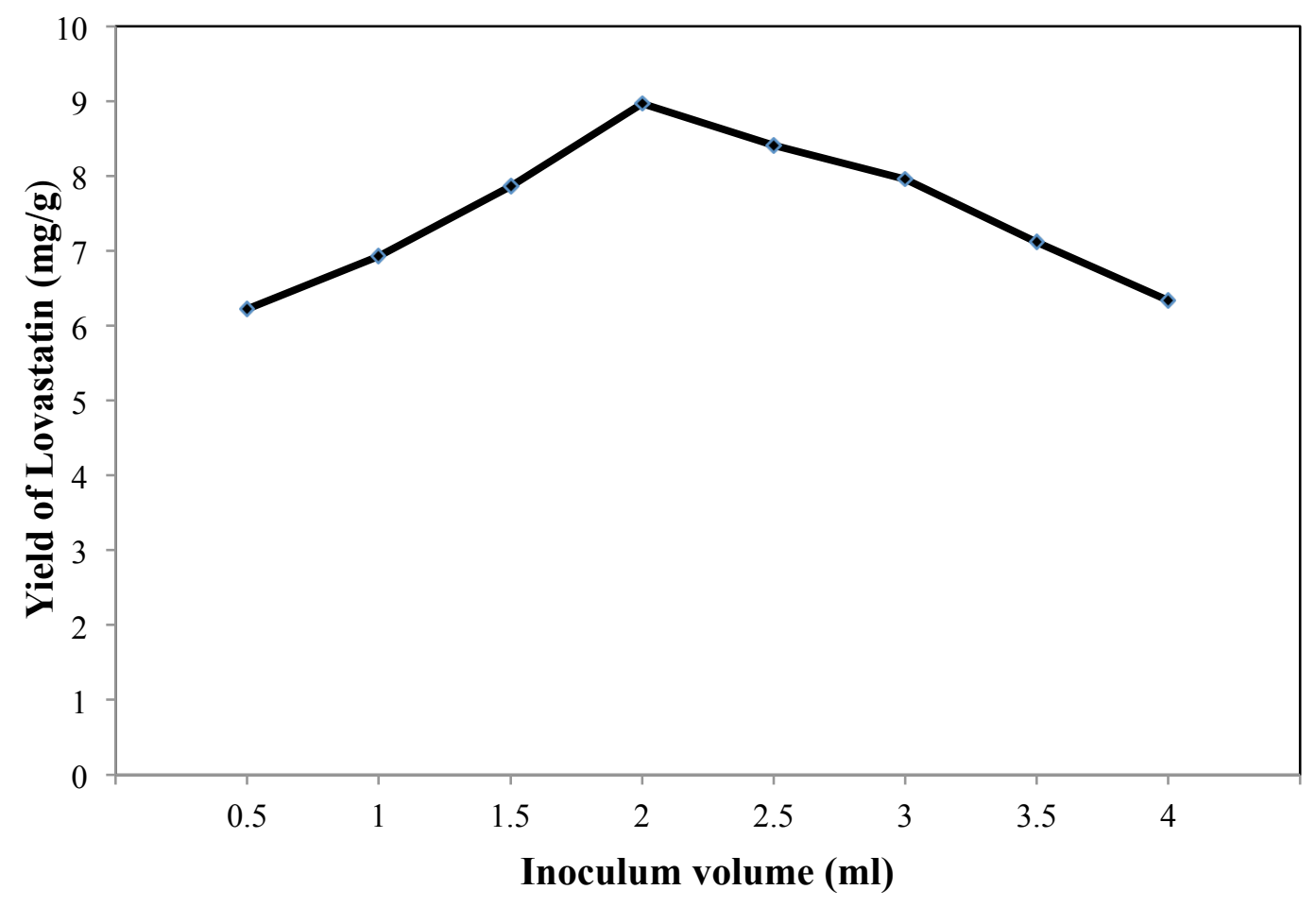

Fig. 3: Effect of inoculum volume on lovastatin production

\section{Effect of initial pH:}

Experiments were performed to the optimum $\mathrm{pH}$ in order to maintain the favorable conditions for increased production of lovastatin. This was established by carrying out the fermentation by varying the $\mathrm{pH}$ from 4-10.

The profound effect of initial $\mathrm{pH}$ of the fermentation on lovastatin production was as shown in Fig. 4. Maximum lovastatin yield
(9.71 $\mathrm{mg} / \mathrm{g}$ dry substrate) was recorded at $\mathrm{pH}$ 5.0. A further increase in $\mathrm{pH}$ resulted in gradual decrease of lovastatin production due to the denaturation or inactivation of the microbial strain, because $\mathrm{pH}$ strongly influences the transport of various components across the cell membrane which support the cell growth and product formation, and most of the fungi are active in the $\mathrm{pH}$ range of 3.5-7 and also lower $\mathrm{pH}$ avoids the contamination by other microbes. The result was in accordance with the lovastation production using Aspergillus terreus under SSF [8]. 


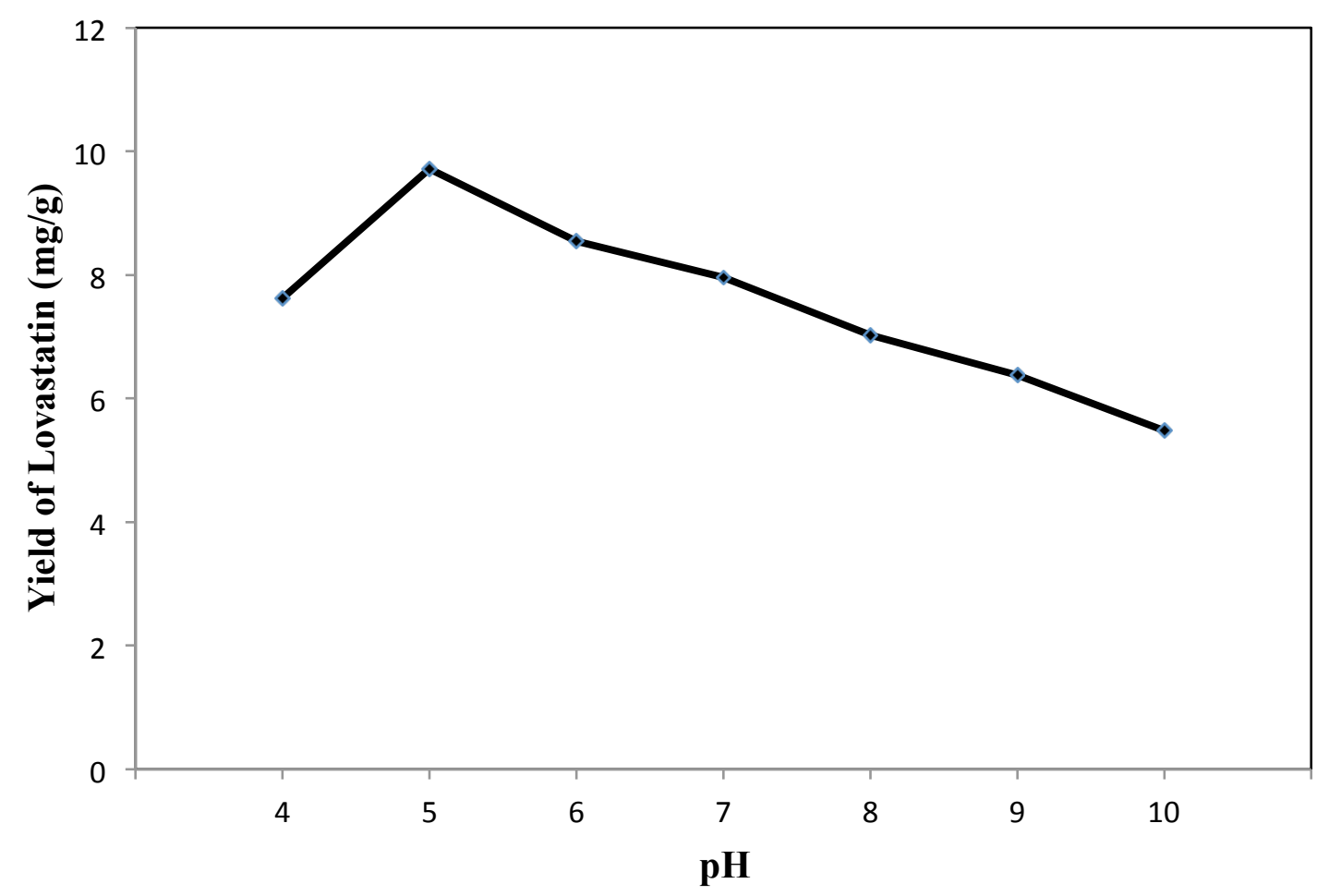

Fig. 4: Effect of pH on lovastatin production.

\section{Effect of temperature}

Fermentation was carried out at various temperatures from $26-40^{\circ} \mathrm{C}$ to study their effect on enzyme production (Fig. 5). Results indicated that maximum lovastatin production $(10.88 \mathrm{mg} / \mathrm{g}$ dry substrate) was obtained when SSF was carried out at $30^{\circ} \mathrm{C}$.

However, lovastatin production reduced gradually above the optimal incubation temperature of $30^{\circ} \mathrm{C}$. With further increase in temperature, more heat is accumulated in the medium during mesophilic aerobic SSF, which leads to poor heat dissipation thus reducing the oxygen level and thereby reducing the growth of microorganism, as lovastatin is growth related product. These results are coinciding with those previously reported for lovastatin production by Aspergillus terreus and Monascus ruber $[10,13]$. 


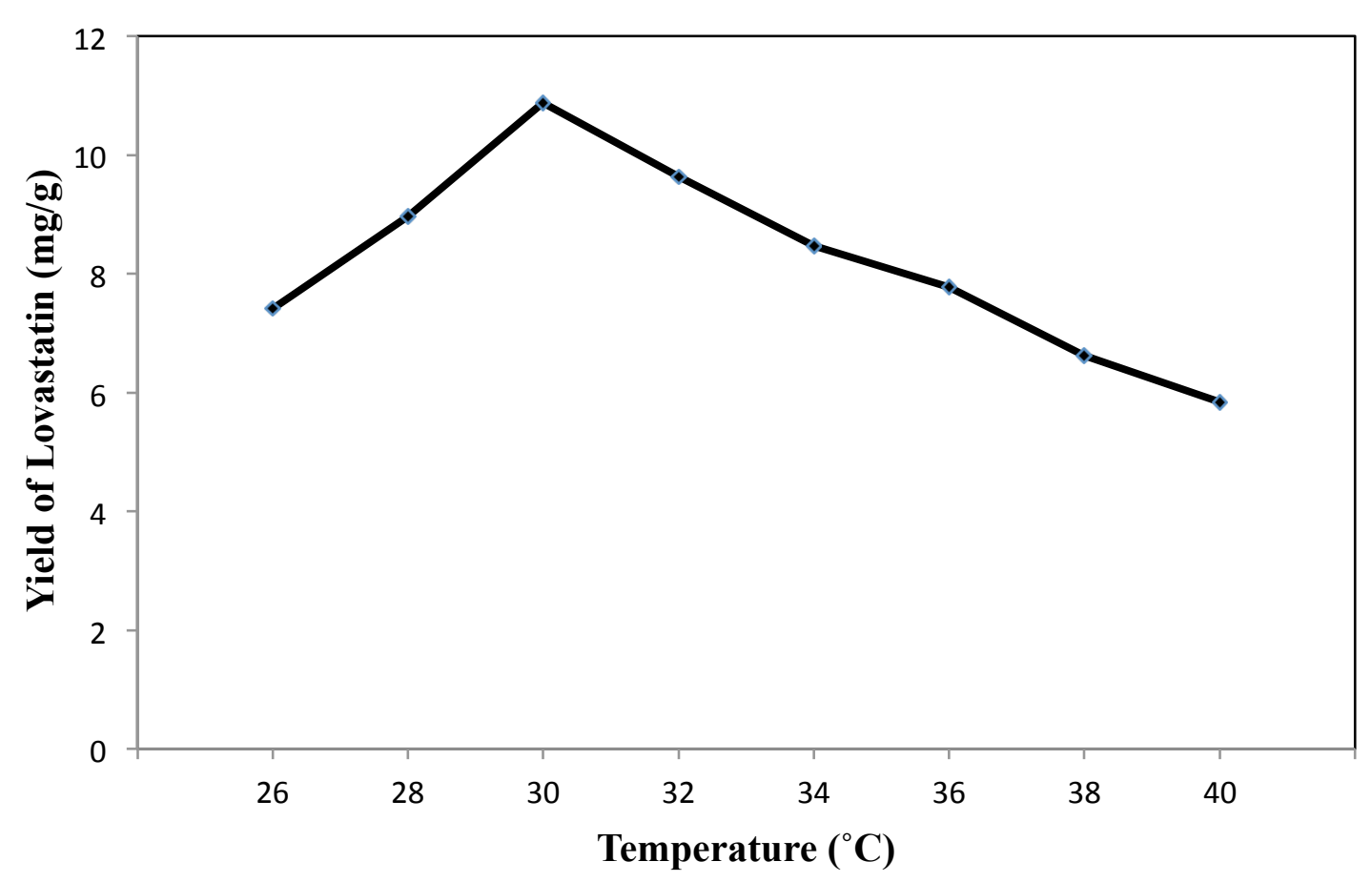

\section{Effect of carbon source}

To determine the effect of incorporation of additional carbon sources on lovastatin yield, different carbon sources namely glucose, maltose, sucrose, xylose, lactose, galactose and soluble starch at $1 \%(\mathrm{w} / \mathrm{v})$ added to the basal solid state fermentative medium of $A$. fischeri exerted a considerable effect on the biosynthesis of lovastatin (Fig. 6). Maximum lovastatin production was promoted by lactose $(12.02 \mathrm{mg} / \mathrm{g}$ dry substrate) followed by maltose $(11.11 \mathrm{mg} / \mathrm{g}$ dry substrate) and sucrose (10.47 mg/g dry substrate). The enhanced production of lovastatin by the incorporation of lactose to the medium might be attributed to the positive influence of lactose as a cometabolic agent for enhanced microbial metabolite biosynthesis.

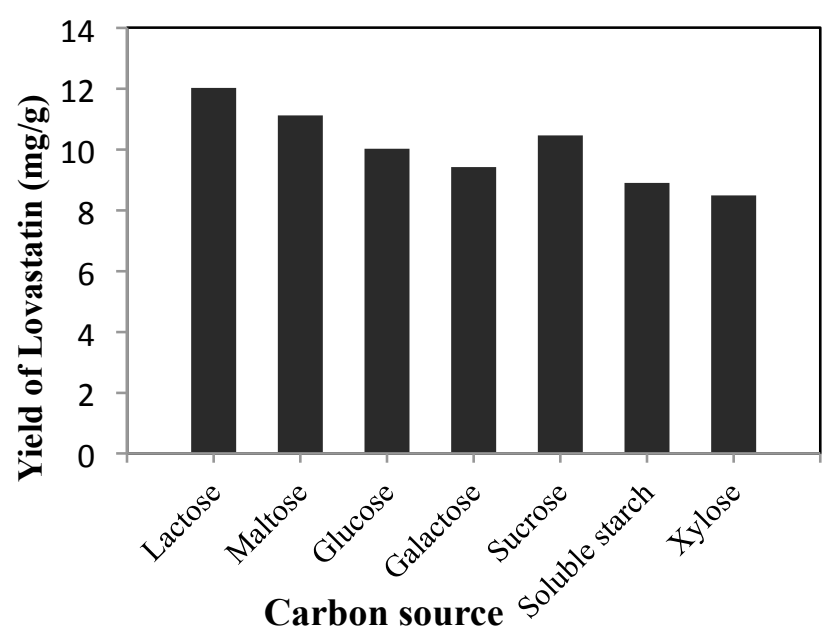

Fig. 6: Effect of different carbon sources on lovastatin production. 


\section{Effect of Nitrogen source}

Nitrogen source can be an important limiting factor in the production of microbial metabolites [14]. The supplementation of additional nitrogen sources (either organic or inorganic) such as sodium nitrate, ammonium sulphate, urea, peptone, tryptone, yeast extract, malt extract and beef extract at $1 \%$ (w/v) had shown a profound impact on the production of lovastatin by $A$. fischeri under SSF ( Fig. 7).

Among the various nitrogen sources evaluated, malt extract in the fermentation medium promoted enhanced fungal growth and consequent lovastatin production of 14.77 $\mathrm{mg} / \mathrm{g}$ dry substrate was achieved followed by yeast extract (12.36 mg/g dry substrate) and sodium nitrate (11.03 mg/g dry substrate).

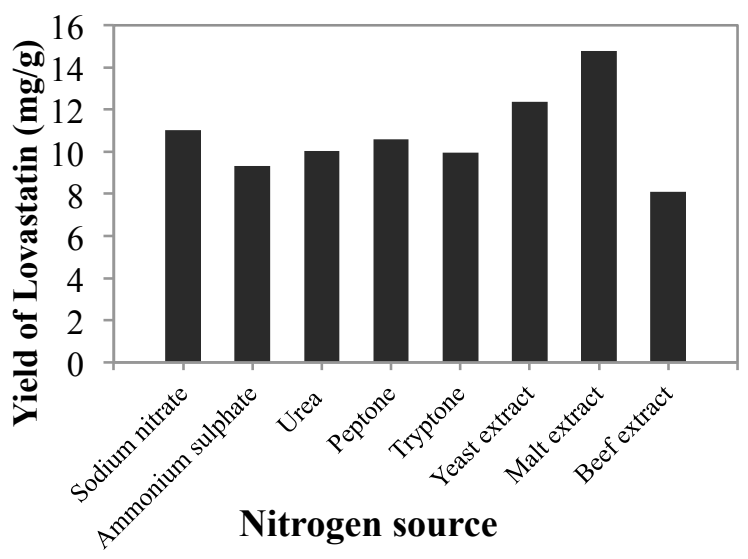

Fig. 7: Effect of different nitrogen sources on lovastatin production

\section{Conclusion:}

The current investigation was mainly focused on the evaluation of the potentiality of Aspergillus fischeri for utilization of coconut oil cake as the substrate for the production of lovastatin under solid state fermentation. The yields obtained in the present study have to be further increased for its industrial importance. It has proved the feasibility of solid state fermentation as a promising technique in exploiting cheaply available agro-residual wastes as substrates for the large-scale production of microbial metabolites of biotechnological importance ultimately leading to an effective solid waste management. 


\section{References:}

1. Alberts AW: Lovastatin and Simvastatin-inhibitors of HMG CoA reductase and cholesterolbiosynthesis: Cardiology 1990, 77:1421.

2. Alberts AW, Chen J, Kuron G, Hunt V, Huff J, Hoffman C, Rothrock J, Lopez M, Joshu H, Harris E, Patchett A, Monaghans R, Currie S, Stapley E, Alberts SG, Hensens O, Hirshfield T, Hoogsteent J, Liescht J, Springeri J: Mevinolin: A highly potent competitive inhibitor of hydroxymethylglutaryl-coenzyme A reductase and a cholesterol-lowering agent. Proc. Natl. Acad. Sci. 1980, 77 (Suppl. 7): 3957-3961.

3. Seenivasan A, Subhagar S, Aravindan R, Viruthagiri T: Microbial production and biomedical applications of lovastatin. Ind. J. of Pharm. Sciences 2009, 701-709.

4. Jones KD, Couldwell WT, Hinton DR, $\mathrm{Su} \mathrm{YH}, \mathrm{He} \mathrm{DK}$, Anker L, Law RE: Lovastatin induces growth inhibition and apoptosis in human malignant glioma cells. Biochem. Biophys. Res .Commun. 1994, 205:1681-1687.

5. Newman A, Clutterbuck RD, Powles RL, Millar JL: Selective inhibition of primary acute myeloid leukemia cell growth by lovastatin. Leukemia 1994, 8:2022-2029.

6. Casas Lopez JL, Sanchez Perez JA, Fernandez Sevilla JM, Acien Fernandez FG, Molina Grima E, Chisti Y: Production of lovastatin by Aspergillus terreus: effects of the C: N ratio and the principal nutrients on growth and metabolite production. Enzyme Microbiol Technol. 2003, 33(Suppl. 2-3): 270-277.

7. Sitaram Kumar M, Jana SK, Senthil V, Shashanka V, Vijayakumar S, Sadhukhan AK: Repeated fed batch process for improving lovastatin production. Process Biochem. 2000, 36 (Suppl. 4): 363-368.

8. Valera HR, Gomes J, Lakshmi S, Gurujara R, Suyanarayan S, Kumar D: Lovastatin production by solid state fermentation using Aspergillus flavipes. Enzyme Microbiol Technol. 2005, 37 (Suppl. 5): 521-526.

9. Xu BJ, Wang QJ, Jia XQ, Sung CK: Enhanced Lovastatin Production by Solid State Fermentation of Monascus ruber. Biotechnol and Bioprocess Engg. 2005, 10 (Suppl. 1):78-84.

10. Pie-Lian WEI, Zhi-nan XU, Pei-Lin CEN: Lovastatin production by Aspergillus terreus in Solid-State fermentation. J. Zheijan Univ. 2007, 9:1521-1526.

11. Mielcarek J, Naskreni M, Grobelny P: Photochemical properties of simvastatin and lovastatin by radiation. $J$. Thermal Analysis Calorimetry 2009, 96:301-305.

12. Pansuriya RC, Singhal RS: Response surface methodology for optimization of production of Lovastatin by solid state fermentation. Brazilian $J$. Microbiol. 2010, 41:164-172.

13. Panda BP, Javed S, Ali M: Optimization of fermentation Parameters for higher lovastatin 
production in Red mold rice through co-culture of Monascus purpureus and Monascus ruber. Food Bioprocess Technol. 2008, 53:342-346.

14. Chandrasekaran

Lashmanaperumalsamy

M,

Chandramohan D: Combined effect of environmental factors on spoilage bacteria. Fish Technology (India) 1991, 28: 146-153. 